\title{
Ultrastructure and localisation of late-sporogonic developmental stages of Sphaerospora ranae (Myxosporea: Sphaerosporidae)
}

\author{
Miloslav Jirků and Pavla Bartošová-Sojková
}

Institute of Parasitology, Biology Centre of the Academy of Sciences of the Czech Republic, České Budějovice, Czech Republic

\begin{abstract}
Data on external ultrastructure of myxospores and internal ultrastructure of advanced pseudoplasmodia and myxospores of topotypic samples of Sphaerospora ranae (Morelle, 1929) from Rana dalmatina Bonaparte are provided, together with in situ hybridisation results. In both frogs examined, the infection was restricted to renal tubules and corpuscles. The infection site restriction was confirmed by light and transmission electron microscopy, as well as by in situ hybridisation. In addition, large myxospore masses measuring up to $500 \mu \mathrm{m}$ were detected in seminal vesicles. Only late-sporogonic stages, i.e. pseudoplasmodia harbouring immature and/or mature myxospores, were observed and analysed. Scanning electron microscopy revealed that spores have smooth surface with exception of posterior valvular bulges, which possess numerous outwards opening internal canals. As revealed by both scanning and transmission electron microscopy, the canals are continuous invaginations of the outer spore surface. Myxospores of S. ranae are characterised by the presence of two uninucleate sporoplasms, bilayered polar capsules, S/H-shaped polar filaments in transversal section and multilayered polar filament eversion pole plugging complex. Ultrastructural observations are discussed in the context of available data for other species of Sphaerospora sensu stricto and apparent synchronisation of myxospore shedding with a brief aquatic breeding phase of vertebrate intermediate host is highlighted.
\end{abstract}

Keywords: Amphibia, Anura, Europe, kidneys, myxospore, Myxozoa, Rana, sporogony, synchronisation, in situ hybridisation

The genus Sphaerospora Thélohan, 1892 is among a few myxosporean taxa well characterised by robust morphological/biological and molecular evidence in congruence with phylogeny (Fiala 2006, Jirků et al. 2007). A recent review and phylogenetic analysis of the most extensive dataset of nominal species of Sphaerospora by Bartošová et al. (2013) confirmed the basal/sister position of the Sphaerospora sensu stricto clade (referred to as Sphaerospora s. s. or sphaerosporids throughout the text) to other myxosporeans, revealed general phylogenetic patterns within the sphaerosporid clade and led to a synonymisation of the genus Polysporoplasma Sitjà-Bobadilla et Alvarez-Pellitero, 1995 with Sphaerospora.

In addition, the same study further discussed the nonsphaerosporid affinity of four nominal Sphaerospora spp.: Sphaerospora dicentrarchi Sitjà-Bobadilla et Alvarez-Pellitero, 1992, Sphaerospora elwhaiensis Jones, Fiala, Prosperi-Porta, House et Mumford, 2011, Sphaerospora oncorhynchi Kent, Whitaker et Margolis, 1993 and Sphaerospora testicularis Sitjà-Bobadilla et Alvarez-Pellitero, 1990.

Two main groups have been identified within the Sphaerospora s. s. clade: Lineage A parasitising marine fish and Lineage B parasitising freshwater and marine/ brackish fish and amphibians. In addition, within the Lineage B, four well supported subclades were clearly identi- fied each characterised by two apparently crucial, biological traits - affinity to particular habitat (marine/brackish $v s$ freshwater) and host taxon (fish $v s$ amphibians). The four B lineages, herein referred to as B1-B4, include: B1 - species from freshwater fish, B2 - species from freshwater/brackish anadromous fish, B3 - species from marine/brackish fish and B4 - species from amphibians.

Although the individual sphaerosporid lineages are well characterised by habitat, host class, sporoplasmic organisation, GC content of rDNA sequences and phylogenetic affinity (Bartošová et al. 2013), the proper interpretation of the phylogeny and full understanding of sphaerosporid evolution require assessment of morphological/structural traits associated with each of the five clades (A and B1-B4). Myxospore gross morphology of Sphaerospora s. s. is relatively simple, providing minimal, if any, additional resolution (Jirků et al. 2007). The only obvious exception is the presence of multiple sporoplasms per spore in representatives of B3 lineage parasitising marine/brackish fish (former Polysporoplasma spp.), opposed by the presence of one binucleate or two uninucleate sporoplasms per spore in other sphaerosporid lineages (Bartošová et al. 2013). Therefore, further assessment of morpho-structural patterns within sphaerosporids might be enhanced by ultrastructural data available for representatives of each of the five sphaerosporid lineages. Ul- 
trastructural information should be preferentially obtained for taxa with known phylogenetic affinity to allow interpretation of data in phylogenetic context. The review by Bartošová et al. (2013) thus provides a suitable baseline for selection of target species. Considering only Sphaerospora s. s. with known phylogenetic position, reasonable ultrastructural data are available for four of the five sphaerosporid lineages. These include (Lineage - species): A - Sphaerospora epinepheli Supamattaya, FischerScherl, Hoffmann et Boonyaratpalin, 1991, Sphaerospora sparidarum (Sitjà-Bobadilla et Alvarez-Pellitero, 2001); B1 - Sphaerospora angulata Fujita, 1912, Sphaerospora dykovae (Dyková et Lom, 1982), Sphaerospora molnari Lom, Dyková, Pavlásková et Grupcheva, 1983; B2 - Sphaerospora elegans Thélohan, 1892, Sphaerospora truttae Fischer-Scherl, el-Matbouli et Hoffmann, 1986; B3 - Sphaerospora sparis (Sitjà-Bobadilla et AlvarezPellitero, 1995) (see Hamilton 1980, Desser et al. 1983, Feist et al. 1991, Supamattaya et al. 1993, McGeorge et al. 1994, Kaup et al. 1995, Sitjà-Bobadilla and AlvarezPellitero 1995, 2001). Thus, the only lineage lacking any ultrastructural data is the Lineage B4 containing sphaerosporids parasitising amphibians.

Sphaerospora ranae (Morelle, 1929) is a member of Lineage B4 (Bartošová et al. 2013). It is a relatively common parasite of the excretory system of western-Palearctic frogs of the genus Rana. Thus far, its occurrence has been confirmed only in Europe in kidneys of Rana dalmatina Bonaparte and Rana temporaria Linnaeus in Belgium, Czech Republic, France (Thélohan 1895, Morelle 1929, Jirků et al. 2007) and Germany (F. Mutschmann, personal communication). Sphaerospora ranae and most other congeners share the general myxospore morphology and localisation of sporogonic development in the excretory system of vertebrate host. The sporogonic stages are coelozoic, occurring in both renal corpuscles and tubules (Jirků et al. 2007).

In this paper, we provide information on external ultrastructure of myxospores and internal ultrastructure of late-sporogonic pseudoplasmodia and myxospores of $S$. ranae from Agile frog Rana dalmatina, together with results of in situ hybridisation (ISH) performed in an attempt to reveal the distribution of developmental stages of $S$. ranae during the terminal stage of sporogony. Finally, we discuss the apparent synchronisation of life cycle of $S$. ranae with phenological phases of the vertebrate amphibian host.

\section{MATERIALS AND METHODS}

Two adult males of Rana dalmatina were collected on 30 March 2012 at night, immediately following observation of the first active individuals after hibernation, i.e. at the very onset of spawning. The animals originated from the type locality of S. ranae: Zaječí potok, Brno, Czech Republic (16036'23"E; $\left.49^{\circ} 14^{\prime} 16^{\prime \prime N}\right)$. Frogs were euthanised by overdosing with barbiturates (Thiopental ${ }^{\circledR}$ Spofa, Prague, Czech Republic) within $24 \mathrm{~h}$ after collection and processed for parasitological exami- nation. Squash preparations of fresh material and histological sections of the following organs were examined by light microscopy using an Olympus BX 51 microscope (Olympus, Tokyo, Japan) equipped with Nomarski differential interferencecontrast optics (NIC): brain, liver, gall bladder, spleen, kidneys, urinary bladder, three equidistantly spaced portions of small intestine, muscle, testes and seminal vesicles. For histology, ISH and transmission electron microscopy (TEM), corresponding samples of brain, liver, gall bladder, spleen, kidneys, three equidistantly spaced portions of small intestine, muscle, testes and seminal vesicles were processed. Samples for histology and ISH were fixed in $10 \%(\mathrm{v} / \mathrm{v})$ buffered formalin for one day and embedded in paraffin; sections for histology were stained with haematoxylin and eosin (H\&E).

Myxospores were isolated from infected kidneys using the modified protocol of Holzer et al. (2003). After dissection, kidneys were stored in PBS or water at $7^{\circ} \mathrm{C}$ for a maximum of $24 \mathrm{~h}$, homogenised and filtred through a 50- $\mu \mathrm{m}$ nylon mesh. Thereafter, spores were separated from the host cells using a two phase system of $5.86 \%$ dextran and $4.5 \%$ polyethylene glycol. To achieve this, $4.82 \mathrm{ml}$ of the filtrate containing $S$. ranae myxospores was mixed with $2.93 \mathrm{ml}$ of $20 \%$ stock dextran solution (Sigma-Aldrich, Prague, Czech Republic) and $2.25 \mathrm{ml}$ of a $20 \%$ stock polyethylene glycol solution (MW 6000; Sigma-Aldrich) in a $10-\mathrm{ml}$ falcon tube. After several inversions the two phases were left to separate for approximately $30 \mathrm{~min}$. The upper sporecontaining polyethylene glycol phase was washed twice with distilled water and centrifuged at $4000 \mathrm{~g}$ for $8 \mathrm{~min}$.

For scanning electron microscopy (SEM), isolated myxospores in PBS or water were allowed to settle on polylysinecoated coverslips for $20 \mathrm{~min}$, at which stage their presence was proved by light microscopy. Coverslips with spores were then fixed in $2.5 \%(\mathrm{v} / \mathrm{v})$ glutaraldehyde in $0.2 \mathrm{M}$ cacodylate buffer (CB), pH 7.2 for $30 \mathrm{~min}$ and washed in $\mathrm{CB}(3 \times 10 \mathrm{~min})$, postfixed for $30 \mathrm{~min}$ in $4 \%(\mathrm{w} / \mathrm{v})$ osmium tetroxide in $\mathrm{CB}(1: 1 \mathrm{ra}-$ tio) and washed with $\mathrm{CB}(3 \times 10 \mathrm{~min})$. After dehydration in graded acetone series, specimens were critical point-dried using $\mathrm{CO}_{2}$, coated with gold, and examined using a JEOL JSM-7401F - FE SEM (JEOL Ltd., Tokyo, Japan) capable of high resolution of up to $1 \mathrm{~nm}$. For TEM, approx. $1-\mathrm{mm}^{3}$ pieces of infected kidneys were fixed overnight with $2.5 \%(\mathrm{v} / \mathrm{v})$ glutaraldehyde in $0.1 \mathrm{M}$ sodium $\mathrm{CB}, \mathrm{pH} 7.2$, postfixed for $2 \mathrm{~h}$ at $4{ }^{\circ} \mathrm{C}$ in $1 \%$ $(\mathrm{w} / \mathrm{v})$ osmium tetroxide, and embedded in Durcupan. Semithin $(400 \mathrm{~nm})$ sections were stained with toluidine blue (TB) and used for additional histological observations. Ultrathin $(70 \mathrm{~nm})$ sections were viewed in a JEOL 1010 TEM (JEOL Ltd.).

For ISH, a modified protocol by Holzer et al. (2003) was used. Sections of examined organs and tissues (see above) were deparaffinised and rehydrated in xylene and a graded ethanol series and then equilibrated in trisbuffered saline (TBS, $\mathrm{pH} 8$ ). For optimal probe penetration to target sequences, sections were permeabilised with $100 \mu \mathrm{g} \cdot \mathrm{ml}^{-1}$ of proteinase K (Serva, Heidelberg, Germany) in TBS (pH 8) for $25 \mathrm{~min}$ at $37^{\circ} \mathrm{C}$. Sections were then washed in phosphate-buffered saline (PBS, $\mathrm{pH}$ 7.4) for $5 \mathrm{~min}$ and post-fixed in $0.4 \%$ paraformaldehyde in PBS for $20 \mathrm{~min}$. After distilled water wash, sections were subsequently dried at $45^{\circ} \mathrm{C}$. Thereafter, each section was framed with $125 \mu \mathrm{l}$ GeneFrame (ABgene Ltd., Epsom, UK) and an ISH mix was pipetted on each framed section. The mix consisted of the ISH buffer ( $4 \times$ saline-sodium citrate buffer (SSC) in TBS containing $0.5 \%$ Ficoll, $0.5 \%$ polyvinylpyrrolidone, and $0.5 \%$ bovine se- 
rum albumin), $100 \mu \mathrm{g} . \mathrm{ml}^{-1}$ calf thymus DNA and $1.5 \mathrm{ng} \cdot \mathrm{ml}^{-1}$ of each oligonucleotide probe. The probes targeting SSU (SRanSSU2020RDIG: 5'-ACTGCCGTTTGCATGAGTTC-3') and LSU (SRanLSU2100RDIG: 5'-ACTGCATCTGCATCCCTGACTTC-3') rDNA of $S$. ranae were designed as reverse oligonucleotides labelled with digoxigenin at the 3 ' end. Sealed with a polyester coverslip over the GeneFrame, the sections were then denatured for $4 \mathrm{~min}$ at $95^{\circ} \mathrm{C}$, and the probes were left to hybridise to complementary sequences for $1.5 \mathrm{~h}$ at $45^{\circ} \mathrm{C}$. The incubation was followed by the removal of the GeneFrame/coverslip set from the slides and by a nonstringent wash in $2 \times$ SSC at $4{ }^{\circ} \mathrm{C}$ to remove the unbound probes. A high stringent wash of $0.2 \%$ SSC containing $0.1 \%$ TWEEN 20 at $45^{\circ} \mathrm{C}$ then ensured the specificity of binding of the probes to the target DNA only.

After the wash in TBS ( $\mathrm{pH} 7.4$ ), the hybridisation signals were detected by incubation with $1: 5000$ anti-DIG-alkaline phosphatase Fab fragments (Roche Diagnostics, Mannheim, Germany) overnight at $4^{\circ} \mathrm{C}$. This step was followed by two thorough washes in TBS $(\mathrm{pH} 8)$ for 5 min each and the final visualisation of the signals with the Vector Blue Alkaline Phosphatase Substrate Kit (Vector Laboratories, Burlingame, USA), resulting in a blue signal. The sections were washed in distilled water and counterstained with $0.1 \%$ Nuclear Fast Red for 3 min resulting in pink to red nuclear staining. After the wash in distilled water and dehydration in 70\%, 95\% and 100\% alcohol and xylene substitute (Sigma-Aldrich), sections were mounted in xylenefree mounting medium Vectamount (Vector Laboratories).

In the following text, we repeatedly refer to Sphaerospora dykovae in the study of Lom et al. (1982) instead of Sphaerospora renicola (Thélohan, 1895) and to $S$. dykovae and S. molnari in the study of Desser et al. (1983) instead of Sphaerospora angulata and S. carassii Kudo, 1919, respectively. To avoid confusion, we would like to stress that species identinfications in these two papers changed in light of the demise of the genus Leptotheca Thélohan, 1895 (see Gunter and Adlard 2010) and recent findings of Holzer et al. (2013a) and Eszterbauer et al. (2013). In fact, a new name $S$. dykovae was introduced for S. renicola Dyková et Lom, 1982 as a consequence of the transfer of mackerel parasite Sphaerospora renicola from the suppressed genus Leptotheca to Sphaerospora. Sphaerospora dykovae is specific to common carp Cyprinus carpio Linnaeus and its sporogonic phase occurs in host's renal tubules. Morphologically similar Sphaerospora angulata has the same tissue tropism as $S$. dykovae but infects goldfish Carassius auratus (Linnaeus) and Prussian carp Carassius gibelio (Bloch). Sphaerospora molnari is a parasite of the gills and skin of common carp in Central Europe. Morphologically similar Sphaerospora chinensis Lom, Dyková, Pavlásková et Grupcheva, 1983 infects gills of common carp in the Far East. Sphaerospora carassii was originally described from the gills of Carassius carassius (Linnaeus) but was also reported from C. gibelio and Rutilus rutilus (Linnaeus) and thus may represent a species complex.

\section{RESULTS}

Infection with Sphaerospora ranae was detected by light microscopy in squashed native preparations of kidneys of both Rana dalmatina examined. Disporic and tetrasporic pseudoplasmodia and free myxospores were observed. Large irregular masses of myxospores measuring up to $500 \mu \mathrm{m}$ were found in seminal vesicles of both frogs

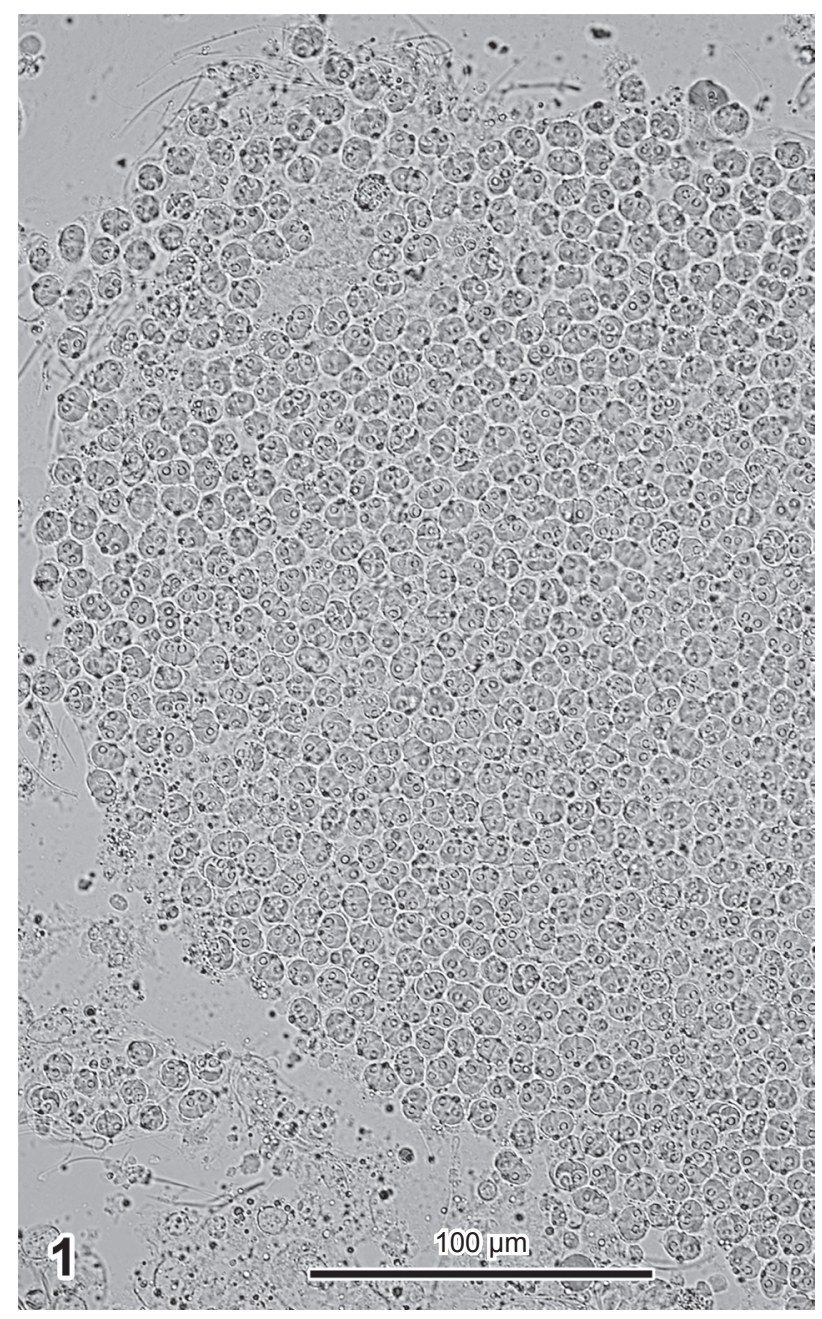

Fig. 1. Mass of myxospores of Sphaerospora ranae from the contents of Rana dalmatina seminal vesicle; native squash preparation, NIC.

(Fig. 1; the spore masses might be in fact smaller if not flattened by a pressure of coverslip). All features typical for $S$. ranae were easily visible in light microscopy. The sporoblast residuum was observed in both myxospores within pseudoplasmodia as well as in released spores as a membraneous bilobed mass of clear colourless substance attached to the posterior part of the spore (see fig. 2L in Jirků et al. 2007). In squash preparations, the sporoblast residuum often ruptured mechanically, leaving just a bilobed halo around the posterior half of the spore.

External ultrastructure of myxospores (Figs. 2-10): In valvular view perpendicular to their longitudinal axis, myxospores broadly elliptical, wider than long, slightly pointed anteriorly, invariably possessing distinct posterior valvular bulges (Fig. 2). Spore surface smooth, only posterior valve bulges dotted with a number of round pits continuous with an extensive intravalvular canal system (Fig. 3). Suture straight, meridional, dividing spore into two symmetrical valves, accompanied by a conspicuous sutural ridge with widened outer rim. Polar filament ever- 


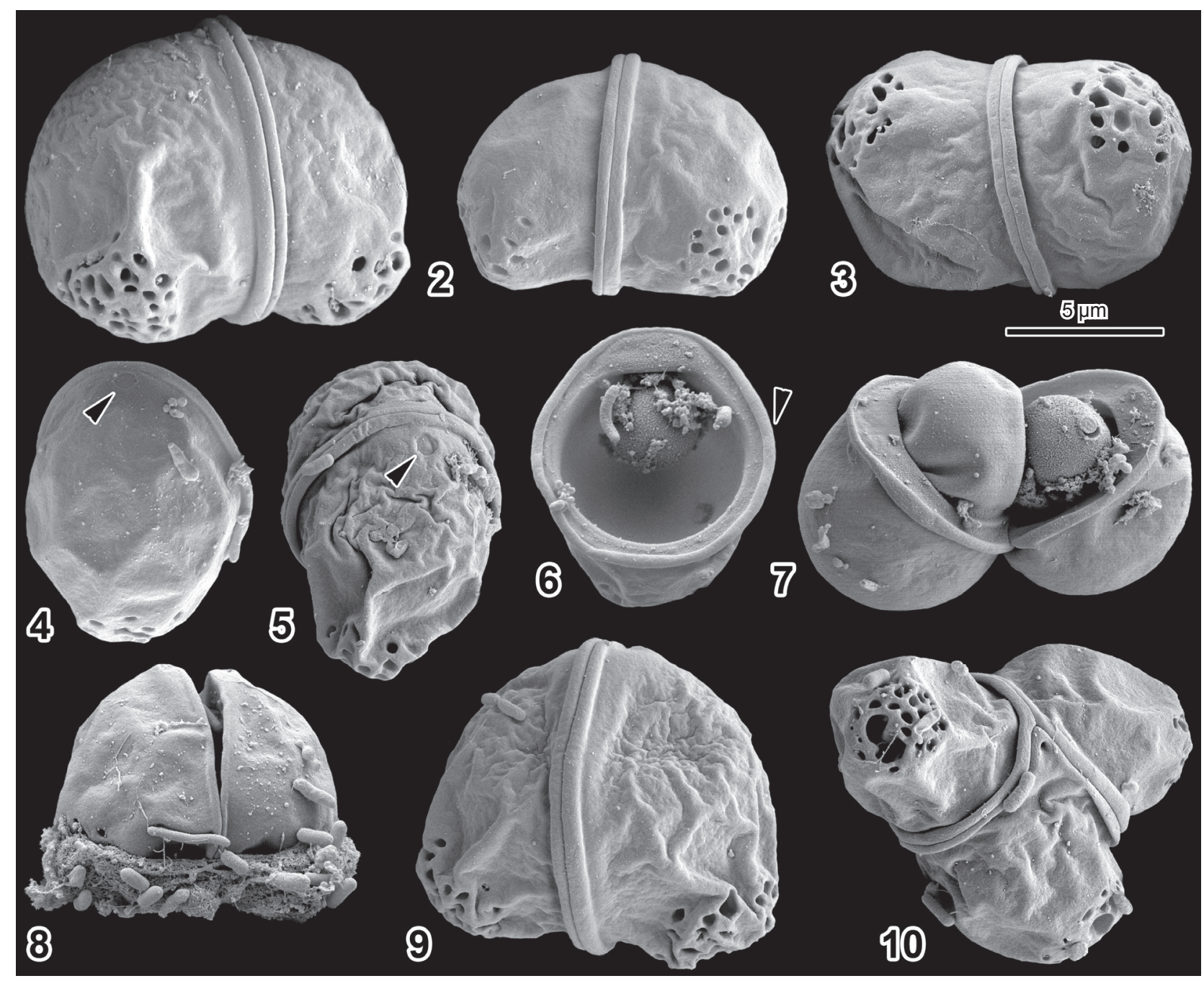

Figs. 2-10. Scanning electron micrographs of myxospores of Sphaerospora ranae isolated from kidneys of Rana dalmatina. All in the same scale. Fig. 2. Valvular view perpendicular to longitudinal axis of the spore. Size extremes are showed. Fig. 3. Posterior view - note the pits on the posterior valvular bulges. Fig. 4. Valvular view - note the polar filament eversion pole (arrowhead) at the apical pole of the spore. Fig. 5. Fronto-lateral view, note the polar filament eversion pole (arrowhead). Fig. 6. Single valve showing polar capsule and roughened surface along the connection zone of valves encircled by a widened outer rim of the sutural ridge (arrowhead). Note the apical thickening above the polar capsule. Fig. 7. Ruptured spore showing sporoplasm (left) and polar capsule with visible plug. Fig. 8. Spore retaining sporoblast residuum on its posterior part. Fig. 9. Spore with partly collapsed wall - note the conspicuous intravalvular sutural ledge along the sutural ridge. Fig. 10. Posterior part of atypical tri-valved spore.

sion poles simple subspherical flat depressions (Figs. 4, 5). In ruptured spores, sometimes still retaining polar capsules, protruded filaments or sporoplasms, somewhat rough surface visible along former connection zone between valves, further encircled by widened outer rim of sutural ridge (Figs. 6, 7). If still present in SEM preparations, sporoblast residuum appears as fibrous mass attached to posterior part of spore (Fig. 8). In SEM preparations, walls of some spores collapsed as a result of processing. In such specimens, intravalvular ledge perpendicular to sutural plane following sutural ridge clearly visible. This sutural ledge gradually widens towards apical pole of spore (Fig. 9). Atypical trivalved spores observed relatively frequently (Fig. 10, see also Jirků et al. 2007).
Pseudoplasmodia, invariably containing advanced myxospores in our preparations, sometimes completely occluded renal tubules (Fig. 11) - a phenomenon observed in most sphaerosporids. If more widely spaced, individual pseudoplasmodia show pseudopodia-like surface projections. As a rule, projections most numerous and conspicuous on side adjacent to microvillar layer of tubular epithelium and on 'upper' (luminal) surface of plasmodium (Fig. 13). Pseudoplasmodia loaf-shaped, with numerous projections around 'flatter' poles. Development of plasmodia seems markedly synchronised as reflected by absence of earlier sporogonic stages, i.e. early plasmodia before formation of differentiated immature spores. Contact between plasmodia and epithelium limited to projections 


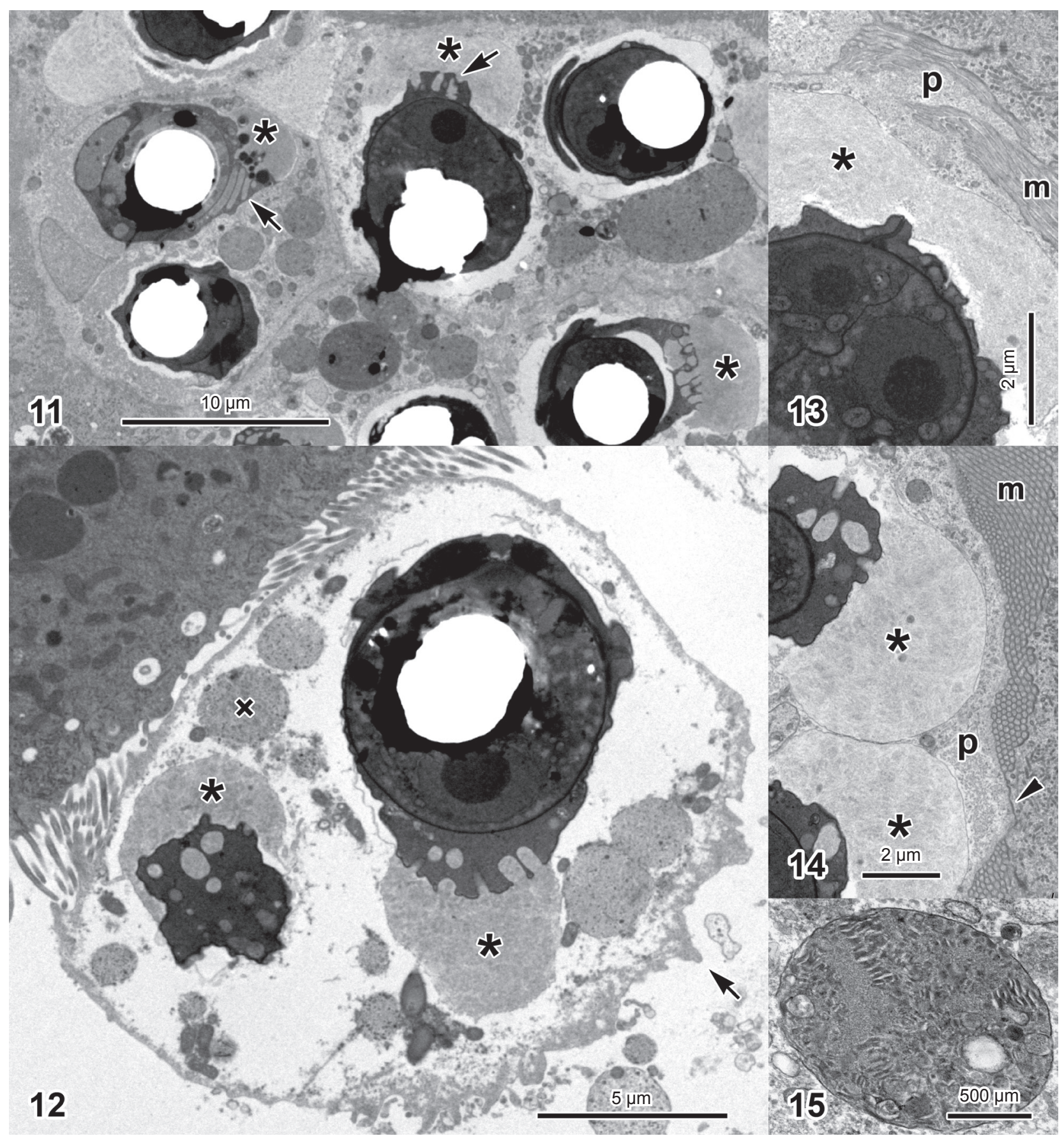

Figs. 11-15. Transmission electron micrographs of pseudoplasmodia of Sphaerospora ranae in renal tubules of Rana dalmatina. Fig. 11. Plasmodia occluding tubule. Microvillar layer of the tubule is appressed to the tubular wall and almost indiscernible. Note sporoblast residuum (asterisks) and canals in the posterior valvular bulges (arrows). Fig. 12. Pseudoplasmodium of typical shape with surface projections on the side adjacent to the tubular microvillar layer and on the luminal side (arrow). Continuity of valvular canals with the sporoblast residua (asterisk) and large membrane bound vesicles in the plasmodial protoplasm (cross) are visible. Fig. 13. Contact zone between pseudoplasmodium and tubular microvillar layer - note the projection of plasmodium (p) inserted between the microvilli (m) and the two uninucleate sporoplasms in the spore surrounded by sporoblast residuum (asterisk). Fig. 14. Contact zone between pseudoplasmodium and tubular microvillar layer - the plasmodium is in direct contact with the intervillar plasmalemma of the tubular cell (arrowhead). Symbols as in Fig. 13. Fig. 15. Large membrane bound vesicle in the plasmodial protoplasm.

or folds of plasmodial surface loosely inserted into tubular microvillar layer (Fig. 12); densely spaced plasmodia in occluded tubules often in direct contact with intervil- lar plasmalemma of epithelial cells (Fig. 14). No specific structures, such as projections or cell junctions, potentially facilitating attachment to host epithelium present. Plas- 


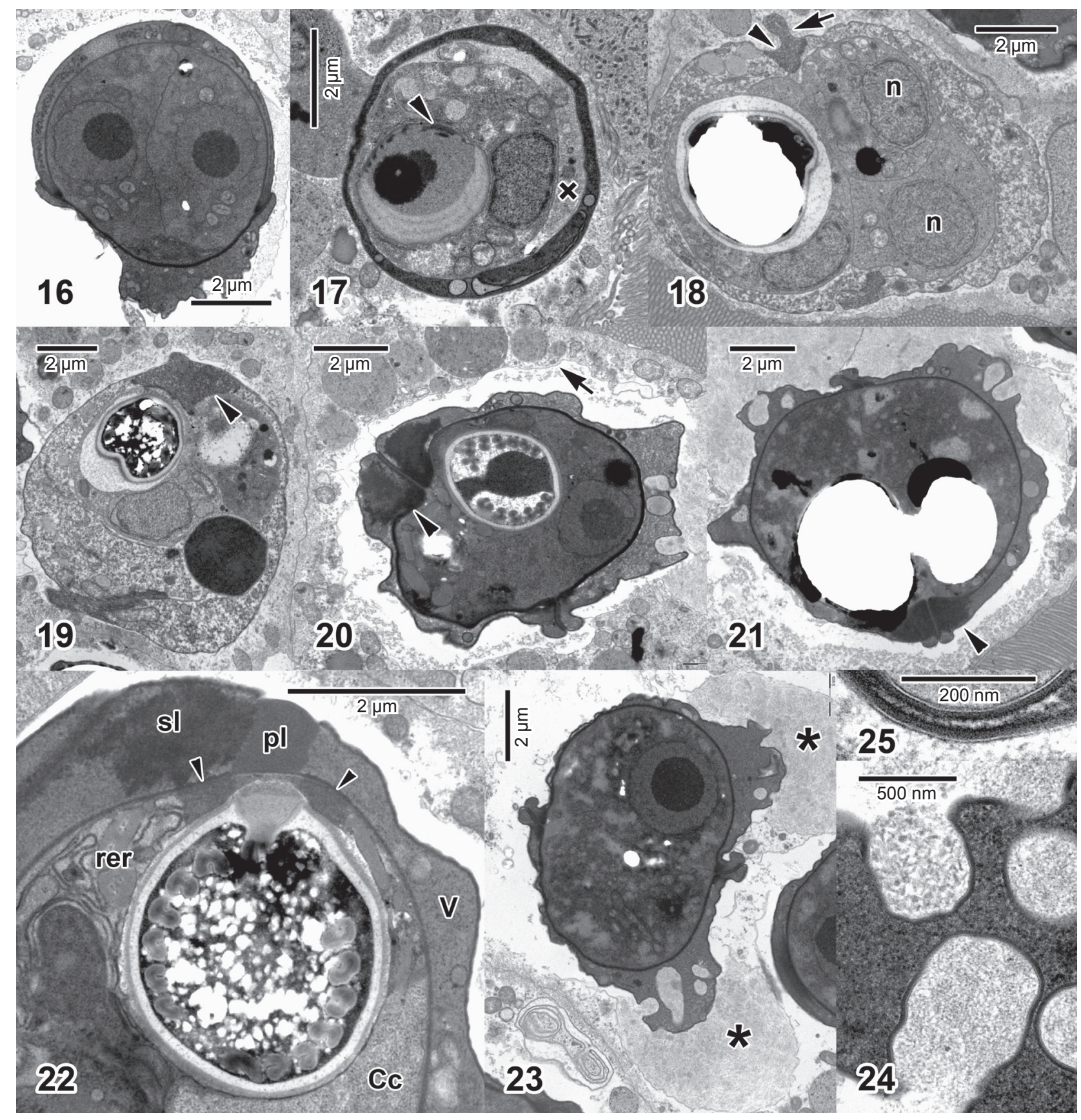

Figs. 16-25. Transmission electron micrographs of myxospores of Sphaerospora ranae from Rana dalmatina. Fig. 16. Posteriorly sectioned spore showing two uninucleate sporoplasms. Fig. 17. Immature spore - a single capsulogenic cell contains polar capsule primordium, nucleus and mitochondria. Marginally sectioned sporoplasmic cell (cross) and a nucleus in the valvogenic cell are visible. Note the electron lucent moon-shaped layer partly encircling the future polar capsule and the early polar filament (arrowhead). Fig. 18. Advanced immature spore showing a capsulogenic cell with polar capsule possessing already bilayered wall, and two sporoplasmic cells with distinct nuclei (n). Note the early sutural ledge (arrowhead) following the sutural ridge (arrow). Fig. 19. Spore in similar stage of development as in Fig. 18. Note the massive thickening of the sutural ledge near the apical spore pole (arrowhead). Fig. 20. Almost mature spore showing the sporoblast membrane (arrow) and a massive sutural ledge near apical spore pole (arrowhead). Fig. 21. Mature spore with fully formed sutural ledge (arrowhead). Fig. 22. Mature polar capsule showing distinct cisternae of rough endoplasmic reticulum (rer) and the typical zonation of the polar filament plugging complex (see text): intravalvular sutural ledge (sl), valvular plug of the polar eversion pole ( $\mathrm{pl}$ ) and extracapsular electron dense ring (small arrowheads) in the capsulogenic cell protoplasm. Note the H/S-shaped polar filament. Symbols: Cc - capsulogenic cell; V - valve. Fig. 23. Posteriorly sectioned spore showing canalisation of the valvular bulges and the membrane bound bilobed sporoblast residuum (asterisk). Fig. 24. Detail of the valvular canals. Fig. 25. High magnification image showing the identity of the outer valvular surface (bottom) and the inner surface (above) of the valvular bulge canal. 


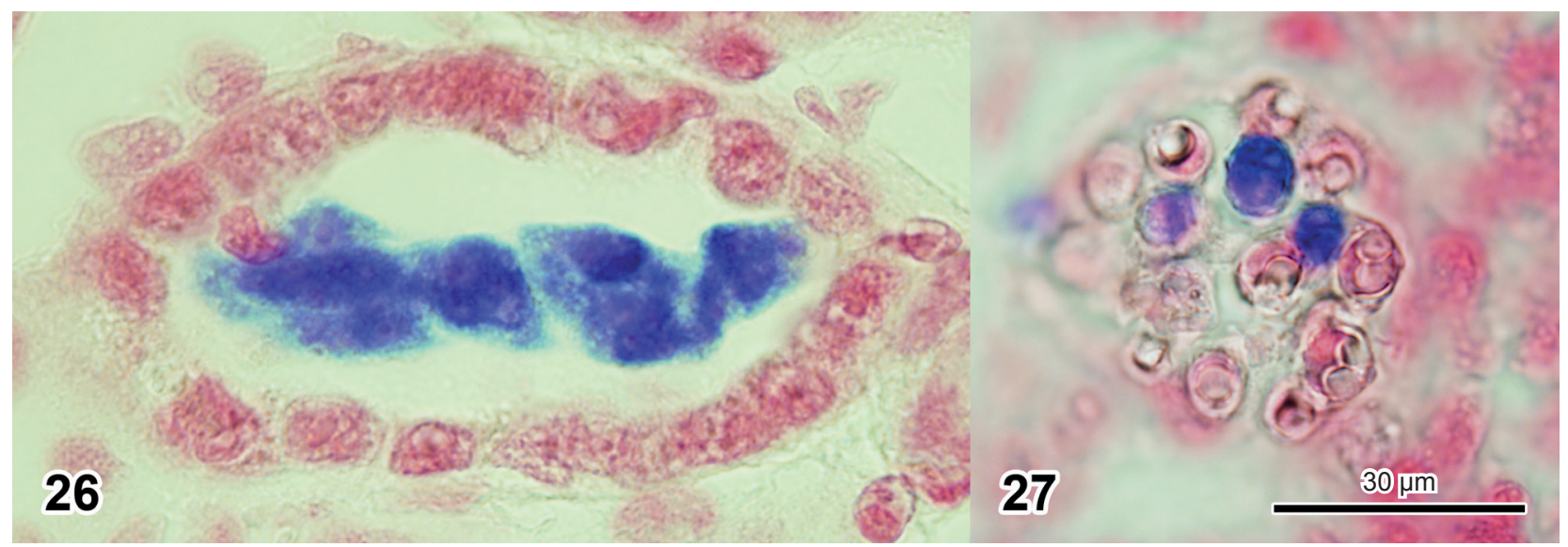

Figs. 26, 27. Micrographs of sporogonic stages of Sphaerospora ranae in renal tubules of Rana dalmatina as revealed by in situ hybridisation. Fig. 26. Group of pseudoplasmodia inside renal tubule - note that the empty space between walls of the tubule and plasmodia is probably a result of shrinking of the plasmodia due to processing. Fig. 27. Myxospores - note that most spores remain unstained or only faintly stained. Both in the same scale.

modia contain mitochondria, various inclusions and small cisternae, and especially large membrane bound spherical vesicles of variable size, ranging between 0.5 and $2.0 \mu \mathrm{m}$ in diameter (Fig. 15). Inside these large vesicles, numerous multi-lamellar structures forming columnar or circular concentric patterns present.

Two uninucleate sporoplasms per spore (Figs. 13, 16). Apart from double membrane-bound nucleus and mitochondria, no distinct organelles visible in sporoplasms. The least advanced spores observed in our preparations contained capsular primordia bound by single electron dense layer corresponding to future outer layer of polar capsule (Fig. 17). On inner surface of this electron dense layer, thick electron lucent layer occupying approximately $60 \%$ of the primordium perimeter present. This lucent layer corresponds to inner wall layer of future polar capsule. Primordia filled by homogeneous content with electron dense eccentrically located patch and early developing polar filament.

In advanced spores, wall of polar capsules already bilayered, composed of thin electron dense outer layer and thick electron lucent inner layer (Figs. 18-21), which turns inward in apical pole of the polar capsule and forms the outer layer of polar filament (Fig. 22). Sections of polar filaments in fully developed spores usually $\mathrm{H}-$ or S-shaped (H/S), depending on section angle (Figs. 19, 20, 22). Apart from polar capsule and nucleus, lipid droplets and distinct cisternae of rough endoplasmic reticulum present in most advanced capsulogenic cells (Fig. 22).

Bowl-shaped bilayered plug in apical pole of polar capsule (Fig. 22). Its lower layer continuous with inner content of polar filament, whereas upper (outer) layer convex, protruding towards discharge channel in shell valve. This plug, however, is separated from shell valve by thin layer of capsulogenic cell protoplasm, encircled by electron dense ring of condensed capsulogenic cell protoplasm. Located in shell valve, i.e. former capsulogenic cell, polar filament discharge channel itself filled by another electron dense plug. From sutural side, polar filament eversion channel in shell valve is approached by markedly electron dense sutural ledge (Fig. 22). Sutural ledge (including apical valvular thickening) discernible externally in some SEM specimens (Figs. 6, 9, see above) develops together with sutural ridge. Sutural ledge appears as progressively wider electron dense zone as development of spore advances as shown in sequence of figures 18-21.

Both mature and immature spores possess conspicuous vacuolation/canalisation of posterior valvular bulges to which sporoblast residuum attaches as bilobed, single membrane-bound mass of finely hyalinous material (Fig. 23, both vacuolation and sporoblast residuum readily visible in TB and H\&E sections - see Jirků et al. 2007). Canals in posterior valvular bulges merely invaginations, continuous with valvular outer surface, so that both canals and outer valvular surface have identical bilayered structure (Figs. 24, 25). No trace of pansporoblast observed in our preparations, suggesting that each spore develops in its own sporoblast, without another common enveloping cell/membrane.

In situ hybridisation (ISH) (Figs. 26, 27): Among all organs/tissues subjected for ISH, only kidneys revealed positive results, confirming restriction of the sporogony, hence the infection, to kidneys. In kidneys, bright bluestained plasmodia and less intensively stained and/or unstained spores were present exclusively in lumina of renal tubules and Bowman's spaces. No signs of any developmental stages were detected by ISH in the interstitium, epithelial cells of tubules or elsewhere, indicating the absence of histozoic (extratubular) stages during the terminal stage of sporogony. In our preparations, approximately $70-80 \%$ of spores remained only faintly stained, or completely unstained (Fig. 27). 


\section{DISCUSSION}

Comparison of our light- and electron-microscopic preparations indicates that most gross-morphological features of myxospores are discernible using light microscopy. Therefore, once the sporogony stage is reached at the outset of spring, the infection can be readily detected and Sphaerospora ranae reliably determined without necessity of TEM or SEM. Importantly, even relatively fine structures, such as the presence of vacuoles in posterior valvogenic cell bulges, their integrity with cell membrane and opening into outer space, are visible in histology and to some degree in fresh mounts as well (compare observations herein with light microscopy in fig. 3I of Jirků et al. 2007).

The absence of specialised surface plasmodial projections in $S$. ranae potentially facilitating attachment of pseudoplasmodia to host epithelium is also seen in other Lineage B sphaerosporids such as $S$. dykovae and $S$. molnari (Lom et al. 1982, Desser et al. 1983). Interestingly, in both representatives of Lineage A for which ultrastructural data are available, S. epinepheli and S. sparidarum, distinct plasmodial projections apparently facilitating attachment of plasmodia to host epithelium are present (Supamattaya et al. 1993, Sitjà-Bobadilla and AlvarezPellitero 2001). These projections markedly resemble probably homological projections in other renal myxosporeans from marine fish, for example Sphaerospora koreana (Cho et Kim, 2001) (syn. Leptotheca koreana), which is so similar to $S$. epinepheli and $S$. sparidarum in so many aspects (compare Supamattaya et al. 1991, Cho and Kim 2001, Sitjà-Bobadilla and Alvarez-Pellitero 2001), that it is possible to assume that it is a representative of Lineage A. However, plasmodial attachment projections are documented from a single B lineage sphaerosporid, S. truttae (McGeorge et al. 1994, 1996), suggesting that plasmodial attachment projections might not be a unique trait of the marine Lineage A.

In congruence with other ultrastructural studies on Sphaerospora s. s., we did not detect any presence of pansporoblasts (Feist et al. 1991). Our observations thus confirm that myxospores of $S$. ranae develop directly by division of generative cells as in other congeners. As specified by Lom et al. (1982), disporic pseudoplasmodia of sphaerosporids are homologous to disporic pansporoblast. Interestingly, there is a variation in number of myxospores in individual plasmodia of $S$. ranae, which are either di- or tetrasporic, a state confirmed repeatedly (Jirků et al. 2007, present study). Such variation is unique among sphaerosporids, plasmodia of which are mostly disporic, less frequently monosporic, but unlike in $S$. ranae, the number of spores per plasmodium is speciesspecific and usually constant (for details see Bartošová et al. 2013). Therefore, it would be interesting to observe the ultrastructure of early sporogonic stages of $S$. ranae to reveal their initial cellular organisation and subsequent development.
In the present study, we demonstrated the previously suggested, but not explicitly confirmed, presence of two uninucleate sporoplasms in myxospore of $S$. ranae (Jirků et al. 2007). Thus the multiplied number of sporoplasms can be considered a common trait shared by Lineage B sphaerosporids (with 2-12 sporoplasms per spore), which is opposed by the predominance of single binucleate sporoplasms in most Lineage A representatives (Bartošová et al. 2013).

The extensive canalisation of the conspicuous posterior valvular bulges creating a multilayered canal system is a very typical feature of $S$. ranae. Except for B1, similar and obviously homological structure is documented in all members of remaining B lineages (B2-B4), namely in $S$. elegans and apparently $S$. truttae (both B2), polysporoplasmid sphaerosporids $S$. motemarini Holzer, Pecková, Patra, Brennan, Yanes-Roca et Main, 2013, S. sparis (both B3), S. ranae (B4) and in S. galinae Evlanov, 1981 and $S$. mugilis (Sitjà-Bobadilla et Alvarez-Pellitero, 1995) probably also clustering within Lineage B (Lom et al. 1985, Feist et al. 1991, McGeorge et al. 1994, SitjàBobadilla and Alvarez-Pellitero 1995, Holzer et al. 2013b, present study). In Lineage B1 representatives $S$. dykovae and $S$. molnari, the posterior valvular bulges of mature spores are vacuolated, but the vacuoles seem not to open outwards and the posterior valvular bulges are markedly reduced in mature spores, forming a simple posterior transient wall (sensu Dyková and Lom 1997) or possibly projections (Lom et al. 1982, Desser et al. 1983). This combination is known also from $S$. ojiroveci Dyková et Lom, 1997 (see Dyková and Lom 1997).

Vacuolation and canalisation seem to be absent in Lineage A sphaerosporids $S$. epinepheli and $S$. sparidarum (Supamattaya et al. 1993, Sitjà-Bobadilla and AlvarezPellitero 2001). As shown in the present study, the posterior intravalvular canals opening outwards are merely invaginations of the outer valvular surface, the genesis and origin of which remain to be elucidated. As the canals communicate with the outer environment and possibly increase the mass/volume ratio of the myxospores, they might, to some degree, increase floating 'ability' and hence spore dispersal in the aquatic environment. A similar function has been proposed previously for spore surface ridges and projections in other myxosporeans (Fiala and Bartošová 2010).

Another trait variable among sphaerosporids is the shape of polar filament in transversal section in mature myxospores. The polar filament of sphaerosporids is either round or H/S-shaped (depending on section angle). The round polar filament is a rare trait among myxozoans in general. In sphaerosporids it is documented in $S$. angulata, S. dykovae, S. galinae, S. molnari, S. ojiroveci, S. tincae Plehn, 1925 and apparently S. ictaluri Hedrick, McDowell et Groff, 1990 (see Hamilton 1980, Lom et al. 1982, Desser et al. 1983, Lom et al. 1985, Hedrick et al. 1990, Kaup et al. 1995, Dyková and Lom 1997), all 
of which parasitise freshwater fish and thus most probably belong to the Lineage B, as confirmed for $S$. angulata, S. molnari and S. dykovae (all three B1) (Bartošová et al. 2013, Eszterbauer et al. 2013, Holzer et al. 2013a). The H/S-shaped polar filament is known in both marine/ brackish and freshwater species, namely in S. epinepheli, S. sparidarum (both A), S. elegans, S. truttae (both B2), polysporoplasmid sphaerosporids $S$. sparis (B3) and S. mugilis (most probably B3) and $S$. ranae (B4) (Feist et al. 1991, Supamattaya et al. 1993, McGeorge et al. 1994, Sitjà-Bobadilla and Alvarez-Pellitero 1995, 2001, present study).

The mixed presence of both round and $\mathrm{H} / \mathrm{S}$ state was not documented in any sphaerosporid lineage yet. However, polar filaments of immature myxospores are apparently H/S-shaped in all sphaerosporids as shown repeatedly in $S$. molnari, $S$. ictaluri and $S$. ojiroveci, mature spores of which possess round polar filaments (Desser et al. 1983, Hedrick et al. 1990, Kaup et al. 1995, Dyková and Lom 1997). Existing, though still limited, combined ultrastructural and phylogenetic evidence suggests possible acquisition of round polar filaments in the Lineage B1 members, probably representing a more derived group of the Sphaerospora s. s. clade. In contrast, H/S-shaped state is repeatedly confirmed in generally more ancient sphaerosporid Lineages A and B2-B4. It is thus possible to conclude that the $\mathrm{H} / \mathrm{S}$-shape is an ancestral trait, retained also in the majority of other, i.e. non-sphaerosporid myxosporeans. However, additional (combined) ultrastructural and phylogenetic data are necessary to confirm this hypothesis.

In some species with round polar filaments, e.g. $S . d y k$ ovae, $S$. molnari and $S$. ojiroveci, there is a fibrillar zone beneath a lucent outer layer (Desser et al. 1983, Dyková and Lom 1997). Although suggested to be a feature common to all myxozoans (Dyková and Lom 1997), the fibrillar zone was, among sphaerosporids, thus far observed only in the three species mentioned above.

The wall of the polar capsule of most sphaerosporids is composed of a single electron dense outer and a single electron lucent inner layer. The only exception seems to be present in polysporoplasmid sphaerosporids $S$. mugilis and $S$. sparis, in which the inner lucent layer is stratified into a few (apparently five) well separated layers (SitjàBobadilla et al. 1992, Sitjà-Bobadilla and Alvarez-Pellitero 1995, Palenzuela et al. 1999). The polar filament plugging complex observed herein in $S$. ranae seems to be among the most complex in sphaerosporids, being most similar to that of S. elegans (Feist et al. 1991). In general, the plugging complex appears most simple in polysporoplasmid sphaerosporids, in which it is apparently reduced to a single thin electron dense layer closing apical pole of polar capsule (Sitjà-Bobadilla and Alvarez-Pellitero 1995).

As shown above, on the level of ultrastructure, there are relatively few traits that are characteristic for and/ or restricted to certain sphaerosporid lineage(s). Generally, most of the alternative states of individual features/ structures seem to vary within most lineages. However, within Lineage $\mathrm{B}$, polysporoplasmid sphaerosporids seem to possess characteristic features that are probably unique to them - the stratified inner lucent layer of polar capsule wall and the presence of more than two sporoplasms per spore. Importantly, S. ranae seems to deviate from general patterns in sphaerosporids by having variable number of spores per plasmodium (two or four) and a comparatively complex organisation/structure of the multilayered plugging complex associated with polar filament eversion canal/pole, similar to that of S. elegans. In addition, marked vacuolation and canalisation of the posterior valvular bulges seem to be characteristic traits of Lineage B, apparently absent in Lineage A. Interestingly, even within Lineage B, this trait has two states, the posterior valvular bulges are either canalised (as in S. ranae), or just vacuolated. Apparently, there is a striking pattern concerning the presence of round polar filaments in transverse sections in representatives of Lineage B1 vs H/Sshaped polar filament in other sphaerosporids. The round filament thus could have taxonomical and phylogenetic significance.

Two marked biological traits have been observed in $S$. ranae during this study: i) absence of presporogonic and early-sporogonic stages, and ii) mass shedding of myxospores during the onset of post-hibernation activity and spawning of its anuran hosts. Apparently, these observations imply marked seasonality and time-restriction of sporogony and myxospore shedding. It is thus justifiable to hypothesise that both processes are exactly synchronised with very early outset of post-hibernation activity of vertebrate intermediate hosts (western-Palearctic Rana spp. are first active anurans in their range) and their markedly brief breeding/spawning phenological phase (lasting only $\sim 2$ weeks in $R$. dalmatina). No life cycle of any Sphaerospora s. s. is known as the actinospore stages initially ascribed to $S$. dykovae and $S$. truttae (see Molnár et al. 1999, Özer and Wootten 2000) were later shown to be non-sphaerosporid myxosporeans (Holzer et al. 2004, Eszterbauer et al. 2006), but as in other myxozoan taxa, it almost certainly involves aquatic invertebrate definitive host(s). The temporally restricted myxospore shedding is thus most probably aimed at the very short time spent in the aquatic habitat by the host, which is essential for dispersal and exposure of myxospores to presumed definitive hosts. This adaptation might be crucial for the water-borne parasite of a mostly terrestrial host. In addition, this synchronisation is probably further enhanced by the observed formation of large myxospore aggregations in seminal vesicles, maximising number of myxospores shed with semen and urine during the short aquatic phase of host.

In the previous study by Jirků et al. (2007), various sporogonic stages ranging from small multinucleate to 
mature myxospore-bearing pseudoplasmodia were observed in $R$. dalmatina collected at the same season and locality as in this study. This implies that at least in some cases or years, early sporogonic stages can still be present in spring. We re-examined the original histological preparations by Jirků et al. (2007) and found out that the early sporogonic stages were rare and present only in a few samples. We conclude that presence of early sporogonic stages in samples from the 2007 study was probably a result of the slightly earlier collection date of some of previously examined hosts (early March $v s$ end of March in the present study).

Absence of histozoic extrasporogonic $S$. ranae stages as demonstrated by ISH of our material, but the presence of such stages in other Sphaerospora s. s., suggests their occurrence in earlier phases of $S$. ranae infection. Thus, it is probable that extrasporogonic and early sporogonic development are completed before or during the winter hibernation of host lasting $\sim-5$ months (Nečas et al. 1997).

Browne et al. (2006) showed that myxospore shedding of Myxobolus fallax Browne, Scheltinga, Pomering et Mahony, 2002 from testes of an Australian frog Litoria fallax (Peters) is synchronised with host spermiation. Sitjà-Bobadilla and Alvarez-Pellitero (1990) described a similar phenomenon in non-sphaerosporid $S$. testicularis causing significant irreversible pathological changes of infected testes of Dicentrarchus labrax (Linnaeus). Interestingly, the sporogony of $S$. testicularis occurs only in male hosts being directly associated with reduction or loss of spermatozoa. In this species, sporogony is obviously synchronised with the host reproductive cycle, too. Due to the relatively small population size of $R$. dalmatina at the type locality of $S$. ranae, we did not examine female hosts for ethical reasons. Therefore, we cannot confirm/ reject infections in females. It remains unclear whether $S$. ranae represents another example of sporogony and myxospore shedding synchronised with host reproduction. However, it is most probably synchronised with aquatic phases of host, i.e. pre-hibernation, hibernation and breeding (see discussion in Jirků et al. 2007 - pres- ence of myxospores in sediment in a container harbouring infected $R$. dalmatina males was reported in this study, suggesting that spores might be shed also without breeding). Although the internal, for example hormonal, mechanisms underlying the synchronisation might be similar as in M. fallax, the two cases differ markedly in their general mode. Myxospores of the testicular histozoic M. fallax are expelled from the host together with semen during spawning and no accumulation of myxospores within urogenital tract of host, apart from site of sporogony, has been observed (Browne et al. 2006). In contrast, myxospores of $S$. ranae are produced in renal tubules, and are subsequently accumulated in seminal vesicles, where they form large aggregations before being expelled with semen during host breeding. According to their presence at the end of host hibernation, it is obvious that the myxospore aggregations are already being formed during hibernation, not only during the host breeding itself. Finally, it is possible to hypothesise that the marked seasonality of sporogony and myxospore shedding might be relatively common phenomenon in amphibian myxosporeans due to time restriction of the host aquatic exposure phase and general breeding seasonality typical for most amphibian taxa. Of course, exceptions are highly probable in (semi) aquatic amphibian taxa and/or aquatic amphibian larvae, as indicated by a co-occurrence of both sporogonic and extrasporogonic stages of Sphaerospora ohlmacheri (Whinery, 1893) in tadpoles of bullfrog Lithobates catesbeianus (Shaw) (Desser et al. 1986).

Acknowledgements. We would like to thank Marie Fučíková, Ashlie Hartigan and Alena Kodádková (Laboratory of Fish Protistology, Institute of Parasitology, BC ASCR, České Budějovice, Czech Republic), Petra Masařová and Martina Tesařová (Laboratory of Electron Microscopy, Institute of Parasitology, BC ASCR) for technical assistance and correction of English (A.H.). This work was supported by the Czech Science Foundation (project Nos. P506/10/2330 to M.J. and P506/11/P724 to P.B.) and the Institute of Parasitology, BC AS CR (institutional support RVO:60077344).

\section{REFERENCES}

Bartošová P., Fiala I., Jirků M., Cinková M., Caffara M., Fioravanti M.L., AtKinson S.D., Bartholomew J.L., Holzer A.S. 2013: Sphaerospora sensu stricto: taxonomy, diversity and evolution of a unique lineage of myxosporeans (Myxozoa). Mol. Phylogenet. Evol. 68: 93-105.

Browne R.K., Li H., Vaughan M. 2006: Sexually mediated shedding of Myxobolus fallax spores during spermiation of Litoria fallax (Anura). Dis. Aquat. Org. 72: 71-75.

Сно J.B., Kıм K.H. 2001: Light and electron microscopic observations of Leptotheca koreana $\mathrm{n}$. sp. (Myxosporea) in the kidney of cultured rockfish Sebastes schlegeli. Dis. Aquat. Org. 46: 189-195.

Desser S.S., Lom J., Dyкoví I. 1986: Developmental stages of Sphaerospora ohlmacheri (Whinery, 1893) n. comb. (Myxo- zoa, Myxosporea) in the renal tubules of bullfrog tadpoles, Rana catesbeiana, from Lake of Two Rivers, Algonquin Park, Ontario. Can. J. Zool. 64: 2213-2217.

Desser S.S., Molnár K., Horvath I. 1983: An ultrastructural study of the myxosporeans, Sphaerospora angulata and Sphaerospora carassii, in the common carp, Cyprinus carpio L. J. Protozool. 30: 415-422.

Dykoví I., Lom J. 1997: Light and electron microscope observations on Sphaerospora ojiroveci n. sp. (Myxozoa) from the kidney of Pangasius sutchi (Teleostei). Eur. J. Protistol. 33: 444-451.

Eszterbauer E., Marton S., Rácz O.Z., Letenyei M., MolNÁR K. 2006: Morphological and genetic differences among actinosporean stages of fish-parasitic myxosporeans (Myxo- 
zoa): difficulties of species identification. Syst. Parasitol. 65: 97-114.

Eszterbauer E., Sipos D., Forró B., Bartošová P., Holzer A.S. 2013: Molecular characterization of Sphaerospora molnari (Myxozoa), the agent of gill sphaerosporosis in common carp Cyprinus carpio carpio. Dis. Aquat. Org. 104: 59-67.

Feist S.W., Chilmonczyk S., Pike A.W. 1991: Structure and development of Sphaerospora elegans Thélohan 1892 (Myxozoa: Myxosporea) in the sticklebacks Gasterosteus aculeatus L. and Pungitius pungitius L. (Gasterosteidae). Eur. J. Protistol. 27: 269-277.

FialA I. 2006: The phylogeny of Myxosporea (Myxozoa) based on small subunit ribosomal RNA gene analysis. Int. J. Parasitol. 36: $1521-1534$.

Fiala I., Bartošoví P. 2010: History of myxozoan character evolution on the basis of rDNA and EF-2 data. BMC Evol. Biol. 10: 228.

Hamilton R.C. 1980: Ultrastructure of a Sphaerospora sp. (Myxosporida) in goldfish kidneys. Micron 11: 499-500.

Hedrick R.P., McDowell T., Groff J.M. 1990: Sphaerospora ictaluri n. sp. (Myxosporea: Sphaerosporidae) observed in the kidney of channel catfish, Ictalurus punctatus Rafinesque. J. Protozool. 37: 107-112.

Holzer A.S., Bartošová P., Pecková H., Tyml T., Atkinson S., Bartholomew J., Sipos D., Eszterbauer E., Dyková I. 2013a: 'Who's who' in renal sphaerosporids (Bivalvulida: Myxozoa) from common carp, Prussian carp and goldfish molecular identification of cryptic species, blood stages and new members of Sphaerospora sensu stricto. Parasitology 140: $46-60$.

Holzer A.S., Pecková H., Patra S., Brennan N.P., YanesRoca C., Main K.L. 2013b: Severe glomerular disease in juvenile grey snapper Lutjanus griseus L. in the Gulf of Mexico caused by the myxozoan Sphaerospora motemarini $\mathrm{n}$. sp. Int. J. Parasitol.: Parasites and Wildlife. 2: 124-130.

Holzer A.S., Sommerville C., Wootten R. 2003: Tracing the route of Sphaerospora truttae from the entry locus to the target organ of the host, Salmo salar L., using an optimized and specific in situ hybridisation technique. J. Fish Dis. 26: 647-655.

Holzer A.S., Sommerville C., Wootten R. 2004: Molecular relationships and phylogeny in a community of myxosporeans and actinosporeans based on their $18 \mathrm{~S}$ rDNA sequences. Int. J. Parasitol. 34: 1099-1111.

Jirk ̊ M., Fiala I., Modrý D. 2007: Tracing the genus Sphaerospora: rediscovery, redescription and phylogeny of the Sphaerospora ranae (Morelle, 1929) n. comb. (Myxosporea, Sphaerosporidae), with emendation of the genus Sphaerospora. Parasitology 134: 1727-1739.

Kaup F.J., Kuhn E.M., Körting W. 1995: Licht- und Elektronmikroskopische Untersuchungen zur Sporogenese von Sphaerospora molnari in den Kiemenlamellen des Karpfens (Cyprinus carpio). Berl. Munch. Tierarztl. Wochenschr. 108: 206-214.

Loм J., DyкоvÁ I., LнотÁкоvá Š. 1982: Fine structure of Sphaerospora renicola Dyková and Lom, 1982 a myxosporean from carp kidney and comments on the origin of pansporoblasts. Protistologica 18: 489-502.

Lom J., Körting W., Dyкová I. 1985: Light and electron microscope redescription of Sphaerospora tincae Plehn, 1925 and

Received 30 January 2014
S. galinae Evlanov, 1981 (Myxosporea) from the tench, Tinca tinca L. Protistologica 21: 487-497.

McGeorge J., Sommerville C., Wootten R. 1994: Light and electron-microscope observations on extrasporogonic and sporogonic stages of a myxosporean parasite of the genus Sphaerospora Thélohan, 1892 from Atlantic salmon, Salmo salar L., in Scotland. J. Fish Dis. 17: 227-238.

McGeorge J., Sommerville C., Wootten R. 1996: Transmission experiments to determine the relationship between Sphaerospora sp. from Atlantic salmon, Salmo salar, and Sphaerospora truttae: a revised species description for $S$. truttae. Folia Parasitol. 43: 107-116.

Molnár K., El-Mansy A., Szekely C., Baska F. 1999: Experimental identification of the actinosporean stage of Sphaerospora renicola Dykova \& Lom 1982 (Myxosporea: Sphaerosporidae) in oligochaete alternate hosts. J. Fish Dis. 22: 143-153.

Morelle L. 1929: Une myxosporidie nouvelle de la grenouille rousse: Leptotheca ranae nov. sp. Ann. Soc. sci. Bruxelles, Serie B 49: 146-148.

NeČas P., Modrý D., Zavadil V. 1997: Czech Recent and Fossil Amphibians and Reptiles, An Atlas and Fieldguide. Edition Chimaira, Frankfurt am Main, $94 \mathrm{pp}$.

Özer A., Wootten R. 2000: The life cycle of Sphaerospora truttae (Myxozoa: Myxosporea) and some features of the biology of both the actinosporean and myxosporean stages. Dis. Aquat. Org. 40: 33-39.

Palenzuela O., Alvarez-Pellitero P., Sitjà-Bobadilla A. 1999: Glomerular disease associated with Polysporoplasma sparis (Myxozoa) infections in cultured gilthead sea bream, Sparus aurata L. (Pisces: Teleostei). Parasitology 118: 245-256.

Sitjà-Bobadilla A., Alvarez-Pellitero P. 1990: Sphaerospora testicularis sp. nov. (Myxosporea: Sphaerosporidae) in wild and cultured sea bass, Dicentrarchus labrax (L.), from the Spanish Mediterranean area. J. Fish Dis. 13: 193-203.

Sitjà-Bobadilla A., Alvarez-Pellitero P. 1995: Light and electron microscopic description of Polysporoplasma n. g. (Myxosporea: Bivalvulida), Polysporoplasma sparis n. sp. from Sparus aurata (L.) and Polysporoplasma mugilis n. sp. from Liza aurata L. Eur. J. Protistol. 31: 77-89.

Sitjà-Bobadilla A., Alvarez-Pellitero P. 2001: Leptotheca sparidarum n. sp. (Myxosporea: Bivalvulida), a parasite from cultured common dentex (Dentex dentex L.) and gilthead sea bream (Sparus aurata L.) (Teleostei: Sparidae). J. Eukaryot. Microbiol. 48: 627-639.

Sitjà-Bobadilla A., Franco-Sierra A., Alvarez-PelliteRo P. 1992: Sphaerospora (Myxozoa: Bivalvulida) infection in cultured gilt head sea bream, Sparus aurata L.: a preliminary report. J. Fish Dis. 15: 339-343.

Supamattaya K., Fischer-Scherl T., Hoffmann R.W., Boonyaratpalin S. 1991: Sphaerospora epinepheli n. sp. (Myxosporea: Sphaerosporidae) observed in grouper (Epinephelus malabaricus). J. Protozool. 38: 448-454.

Supamattaya K., Fischer-Scherl T., Hoffmann R.W., BOONYARATPALIN S. 1993: Light and electron microscope observations on presporogonic and sporogonic stages of Sphaerospora epinepheli (Myxosporea) in grouper (Epinephelus malabaricus). J. Eukaryot. Microbiol. 40: 448-454.

Thélohan P. 1895: Recherches sur les Myxosporidies. Bull. Sci. France et Belgie. 26: 100-394. 